macular oedema, which may have been a confounding factor. However, the authors mention diabetes as a risk factor for BRVO; therefore, excluding these patients is excluding a large patient group from this treatment.

\section{Answer 6}

As you know, an increased risk of BRVO has been suggested in persons with a history of systemic hypertension, atherosclerosis, cardiovascular disease, glaucoma, high body mass index, and inflammatory or thrombophilic conditions that may lead to retinal endothelial vascular damage. The interruption of venous flow in these eyes almost occurs at a retinal arteriovenous intersection, where a retinal artery crosses a retinal vein. Arterial compression of the vein is believed to be the main cause of BRVO. Compression of the vein may lead to turbulent flow in the vein. The turbulent flow in combination with the pre-existing endothelial vascular damage from the different conditions creates a local environment favourable to intravascular thrombus formation. The most common causes of BRVO are systemic hypertension and atherosclerosis. Diabetes mellitus is relatively a very low-risk factor. Moreover, some authors alleged that diabetes mellitus is not risk factor for BRVO.

In our study, a detailed history of the patients was obtained to evaluate the effect of IVTA in the treatment of persistent macular oedema in branch retinal vein occlusion. Therefore, excluding these patients does not mean excluding a large patient group from this treatment. The efficacy of IVTA in patients with diabetic macular oedema was reported in our another study. ${ }^{7}$

\section{References}

1 Martidis A, Duker JS, Greenberg PB, Rogers AH, Puliafito $\mathrm{CA}$, Reichel $\mathrm{E}$ et al. Intravitreal triamcinolone for refractory diabetic macular edema. Ophthalmology 2002; 109(5): 920-927.

2 Ito M, Okubo A, Sonoda Y, Yamakiri K, Sakamoto T. Intravitreal triamcinolone acetonide for exudative age-related macular degeneration among Japanese patients. Ophthalmologica 2006; 220(2): 118-124.

3 Ozkiris A, Evereklioglu C, Oner A, Erkilic K. Pattern electroretinogram for monitoring the efficacy of intravitreal triamcinolone injection in diabetic macular edema. Doc Ophthalmol 2004; 109(2): 139-145.

4 Ozkiris A, Erkilic K. Complications of intravitreal injection of triamcinolone acetonide. Can J Ophthalmol 2005; 40(1): 63-68.

5 Ozkiris A, Evereklioglu C, Erkilic K, Ilhan O. The efficacy of intravitreal triamcinolone acetonide on macular edema in branch retinal vein occlusion. Eur J Ophthalmol 2005; 15(1): 96-101.

6 Ozkiris A, Evereklioglu C, Erkilic K, Dogan H. Intravitreal triamcinolone acetonide for treatment of persistent macular oedema in branch retinal vein occlusion. Eye 2006; 20(1) 13-17.

7 Ozkiris A, Evereklioglu C, Erkilic K, Tamcelik N, Mirza E. Intravitreal triamcinolone acetonide injection as primary treatment for diabetic macular edema. Eur J Ophthalmol 2004 14(6): 543-549.

\section{A Özkiriş}

Department of Ophthalmology, Erciyes University

Medical Faculty, Yıldırım Beyazıt mah. Mustafa

Simsek, Cad. Kardelen Apt. No.: 121/16,

Melikgaz, Kayseri TR-38030, Turkey

Correspondence: A Özkiriş,

Tel: + 90352 4374901;

Fax: + 903524374912

E-mail: aozkiris@erciyes.edu.tr

Eye (2007) 21, 254-255. doi:10.1038/sj.eye.6702489; published online 28 July 2006

Sir,

\section{Reply to Ozkiris et al}

I read with interest the study by Ozkiris et $a l^{1}{ }^{1}$ and feel it poses several interesting points.

The technique of administering the intravitreal injection, and the optimum dosage required to gain a therapeutic benefit still remains a matter of debate. Ozkiris and co-workers administer intravitreal triamcinolone acetonide (IVTA) after performing an anterior chamber paracentesis; in practice, this may be difficult as one is injecting into an already 'soft' eye. However, there seems to be a wide variation in injection technique, and few appear to be evidence-based, as highlighted in a recently published survey. ${ }^{2}$ The dosage for several studies looking at the use of IVTA in the treatment of macular oedema in branch retinal vein occlusions is $4 \mathrm{mg}^{3-5}$ and in one study was $20-25 \mathrm{mg}{ }^{6}$ Ozkiris and co-workers used $8 \mathrm{mg}$ to treat their patients, but the reasoning for this dose is not commented upon. The varying doses administered to patients in different studies can make it difficult to draw any definite conclusions about the appropriate therapeutic dose.

A statistically significant improvement in visual acuity (VA) was seen after IVTA, with the maximal response between 1 and 3 months postinjection. This suggests that in order to maintain the best-achieved VA, repeat injections may be necessary. The authors do not comment on whether they would recommend repeat injections, 
either to maintain the post-treatment improvement in VA in those that responded, or to treat the two cases that were refractory to initial ITVA. In addition, the short follow-up time in this study (6.2+/1.0 months) makes it difficult to come to any conclusion about the long-term efficacy of this treatment.

Repeated intravitreal injections are not without risk - the authors did not report any injection- or corticosteroid-related complications. The risk of endophthalmitis is the most feared complication; however, varying problems from conjunctival necrosis to intraocular lens dislocation have been documented with intravitreal injection. ${ }^{7,8}$ In addition, progression of cataract is a well-recognised risk, and it has been suggested that this is related to the number of intravitreal injections administered to a patient. ${ }^{3}$ The situation may be further confounded as cataract surgery may aggravate macular oedema in the very eyes that have been treated with repeat injections.

The authors do not discuss their feelings on the statistically significant intraocular pressure (IOP) rise postinjection, except to mention that one eye with a persistently elevated IOP was successfully treated with topical medication. Glaucomatous eyes may not be able to tolerate the increase in IOP postinjection, even if it is within the normal range, and indeed some patients with pre-existing glaucoma may need to be treated by filtration surgery. In addition, after IVTA, that IOP may take as long as 8-9 months to return to preinjection values; ${ }^{9}$ this means that patients may have to be on topical treatment for a considerable time, with their attendant side effects.

The exclusion criteria of the study excluded patients if they had diabetes mellitus, presumably owing to either the potential corticosteroid-related complications associated with this intervention or because of any coexisting macular oedema that may have been a confounding factor. However, the authors mention diabetes as a risk factor for branch retinal vein occlusion (BRVO); therefore excluding these patients is excluding a large-patient group from this treatment. It does not have appeared to be part of exclusion criteria in other similar studies, ${ }^{6}$ and indeed ITVA used in studies to treat refractory diabetic macular oedema. ${ }^{10}$

It seems that IVTA requires further evaluation in relation to its role in the treatment of macular oedema in BRVOs.

\section{References}

1 Ozkiris A, Evereklioglu C, Erkilic K, Dogan H. Intravitreal triamcinolone acetonide for treatment of persistent macular oedema in branch retinal vein occlusion. Eye 2006; 20: 13-17.
2 Anijeet DR, Hanson RJ, Bhagey J, Bates RA. National survey of intravitreal triamcinolone injection in the United Kingdom. Eye, (advance online publication, 27 January 2006. doi: 10.1038/sj.eye.6702232).

3 Cekic O, Chang S, Tseng JJ, Barile GR, Del Priore LV, Weissman $\mathrm{H}$ et al. Intravitreal injection for treatment of macular oedema secondary to branch retinal vein occlusion. Retina 2005; 25(7): 851-855.

4 Karacorlu M, Ozdemir H, Karacorlu SA. Resolution of serous macular detachment after intravitreal triamcinolone treatment of patients with branch retinal vein occlusion. Retina 2005; 25(7): 856-860.

5 Krepler K, Ergun E, Sacu S, Richter-Muksch S, Wagner J, Stur $\mathrm{M}$ et al. Intravitreal triamcinolone acetonide in patients with macular oedema due to branch retinal vein occlusion: a pilot study. Acta Ophthalmol Scand 2005; 83(5): 600-604.

6 Jonas JB, Akkoyun I, Kamppeter B, Kreissing I, Degenring RF. Branch retinal vein occlusion treated by intravitreal triamcinolone acetonide. Eye 2005; 19: 65-71.

7 Srinivasan S, Prasad S. Conjunctival necrosis following intravitreal injection of triamcinolone acetonide. Cornea 2005; 24(8): 1027-1028.

8 Degenring RF, Sauder G. Vitreous prolapse and IOL dislocation during intravitreal injection of triamcinolone acetonide. Graefes Arch Clin Exp Ophthalmol 2005; 20: 1-2.

9 Jonas JB, Degenring RF, Kreissig I Akkoyun I, Kamppeter B. Intraocular pressure elevation after intravitreal triamcinolone acetonide injection. Ophthalmology 2005; 112(4): 593-598.

10 Martidis A, Duker JS, Greenberg PB, Rogers Ah, Puliafito $\mathrm{CA}$, Reichel $\mathrm{E}$ et al. Intravitreal triamcinolone for refractory diabetic macular oedema. Ophthalmology 2002; 109: 920-927.

S Pathai

QEIl Hospital, North and East Herts NHS Trust, Ophthalmology, Howlands, Welwyn Garden City, Herts AL7, UK

Correspondence: S Pathai,

Tel: + 441707 365049;

Fax: + 441438355296.

E-mail: sophia.pathai@ukonline.co.uk

Eye (2007) 21, 255-256. doi:10.1038/sj.eye.6702486; published online 16 June 2006

Sir,

Operating conditions for ocular surgery under general anaesthesia: an eccentric problem

Rossiter et $a l^{1}$ have written a timely reminder of the problems that may result from Bell's reflex in the nonparalysed patient undergoing cataract surgery under general anaesthesia.

Bell's reflex can also be a problem in strabismus surgery leading to difficulties in interpretation of the 